\title{
Lhermitte's sign in subacute combined degeneration of the cord
}

\author{
P. C. GAUTIER-SMITH
}

From the National Hospitals for Nervous Diseases, London

SUMMARY Lhermitte's sign is a common early symptom of subacute combined degeneration of the cord occurring in 11 out of 44 patients admitted to the National Hospitals for Nervous Diseases during the decade 1962-71 with this diagnosis. Two patients, in both of whom it was the presenting complaint, are described in detail. It is concluded that, in these cases, Lhermitte's sign is due to stretching of demyelinated fibres in the posterior columns in the cervical cord, produced by neck flexion. The symptoms disappear after treatment with vitamin $B_{12}$. The clinical importance of this symptom is emphasized.

It was in 1917 that Marie and Chatelin first described the syndrome that has come to be known as Lhermitte's sign, in the following words:

'... le blessé a la sensation qu'un courant électrique parcourt ses bras et même ses jambes, il en est de même lorsque le blessé baisse fortement la tête sur la poitrine, se baisse ou s'accroupit ...'

These authors thought that the symptomatology, which in their case was due to trauma, was secondary to a radiculopathy, but Babinski and Dubois (1918) considered that it was caused by a cord lesion. Lhermitte (1918) was of the same opinion and later (Lhermitte, Bollak, and Nicolas, 1924) described it in detail in a case of multiple sclerosis. Since that time, Lhermitte's sign has been described in a variety of other conditions including cervical cord tumours and tuberculosis of the cervical spine (Patrick, 1930), cervical spondylosis (Alajouanine, Thurel, and Papaïoanou, 1949), arachnoiditis (McAlpine, Lumsden, and Acheson, 1965), and radiation myelopathy (Jones, 1964).

The occurrence of Lhermitte's sign in subacute combined degeneration of the cord was first described by Hassin (1933), but, since then, there have been very few other reports in the literature. Two cases seen recently suggested that the association might not be so unusual and this view was borne out when it was found that 11 out of the 44 patients admitted to the National Hospitals for Nervous Diseases with subacute combined degeneration of the cord between 1962 and 1971, complained of this symptom at some time in the course of the illness.

\section{CASE 1}

The patient, a housewife aged 48 years, was seen for the first time in July 1969. For two months, she had noticed momentary, shooting, tingling sensations down the arms and legs when flexing her neck. Two weeks later she complained of paraesthesiae in the hands and feet, followed by clumsiness in the use of her fingers.

Physical examination was negative apart from mild impairment of position and vibration sense in the feet and the ankle jerks were depressed.

Investigations revealed: haemoglobin $12.4 \mathrm{~g} /$ $100 \mathrm{ml}$., MCV $109 \mathrm{cu} . \mu$, macrocytes present on the blood film, serum $\mathrm{B}_{12} 80 \mu \mu \mathrm{g} / \mathrm{ml}$., Schilling test part I $2.5 \%$, part II $10.5 \%$. Test meal showed histamine fast achlorhydria; radiographs of the cervical spine showed changes of spondylosis; the narrowest diameter of the cervical canal was $15.5 \mathrm{~mm}$. Nerve conduction studies were normal apart from an absent sensory action potential in the left lateral popliteal nerve. Barium meal was normal.

The patient was treated with daily injections of $1,000 \mathrm{mcg}$ vitamin $B_{12}$ for five days, reducing to maintenance dosage thereafter. Her symptoms, including Lhermitte's sign, disappeared completely within four months and she was in perfect health when last seen in September 1972. 
CASE 2

The patient, a male schoolteacher aged 35 years, was seen for the first time in February 1971. For four months, he had noticed electric-shock-like feelings which ran down the backs of his legs when he bent his neck forwards. The sensation was momentary and invariably precipitated by neck flexion. For two months he had been troubled by paraesthesiae from the costal margin downwards and for three weeks by some clumsiness of the hands.

Examination revealed a smooth tongue and widespread vitiligo. There was impairment of joint position sense in the fingers and toes and vibration sense and cutaneous sensibility were defective below. the costal margin. The tendon reflexes in the legs were absent.

Investigations revealed: haemoglobin $13.3 \mathrm{~g} /$ $100 \mathrm{ml}$., MCV $104 \mathrm{cu} . \mu$; no macrocytes were seen on the blood film, the bone barrow was megaloblastic, serum $B_{12}$ level was $75 \mu \mu \mathrm{g} / \mathrm{ml}$., Schilling test part I $0.5 \%$, part II $17.8 \%$. A test meal showed histamine fast achlorhydria. Radiographs of the cervical spine were normal; the narrowest diameter of the cervical canal was $17.0 \mathrm{~mm}$. Nerve conduction studies were normal apart from an absent sensory action potential in the right lateral popliteal nerve.

This patient was also treated with daily injections of $1,000 \mathrm{mcg}$ vitamin $B_{12}$ for five days, reducing to maintenance dosage thereafter. His symptoms, including Lhermitte's sign, disappeared within three months and he was perfectly well when last seen in September 1972.

\section{DISCUSSION}

In the decade $1962-71,44$ patients with proven subacute combined degeneration of the cord were admitted to the National Hospitals for Nervous Diseases. In 11 of them $(25 \%)$, including the two described in this report, Lhermitte's sign was a prominent complaint.

The symptomatology was remarkably similar in all of them and identical with that described in the early papers by Lhermitte (Lhermitte et al., 1924; Lhermitte, Lévy, and Nicolas, 1927). Momentary electric-shock-like feelings were produced by flexion of the neck. The distribution was variable; most commonly the sensations radiated down the back into the legs, but in one patient they were felt in the arms only and in another just down the back. Although most of these patients had signs of damage to pyramidal tracts and posterior columns, as well as those of a peripheral neuropathy, the one sign common to all of them was loss of position and vibrationo sense in a distribution suggesting a lesion of the posterior columns in the cervical cord. This finding strongly supports the generally acceptec view that damage at this site is a prerequisite fores the production of the symptom.

Lhermitte et al. (1924), discussing the mechan ism in multiple sclerosis, considered that direct. pressure on or elongation of sensory fibres stripped of their insulating myelin sheaths, wasf the cause and thought that it was analogous tof Tinel's sign in peripheral nerve lesions.

In view of the fact that Lhermitte's sign can be produced by extrinsic lesions impinging on then cervical cord, Alajouanine et al. (1949) thoughts that demyelination was not an essential requirement, but Jones (1964) in a carefully reasoned $\omega$ paper considered that the latent interval when? the response followed trauma or radiation damage strongly suggested that the presence of medullary changes was necessary, as the sameir mechanical factors which operated when theog sensations appeared were, in fact, also present the earlier and silent period. He also pointed ơ that, in addition to the fact that the cervical cold may impinge on the vertebrae in front and on thes ligamentum flavum behind on precipitate mo ment of the cervical spine, it also has its posteris fibres elongated on gradual flexion and may $\overrightarrow{D e c}$ distorted in the coronal plane by the restricting action of the denticulate ligaments. These stresses are greatest at the mid-line of the posterior columns and on the posterolateral fibres of theo lateral spinothalamic tracts, which in both caseso would explain the common distribution of Lhermitte's sign in the lumbosacral segments.

In subacute combined degeneration of the spinal cord, Pant, Asbury, and Richardson (1968) pointed out that, although the axons are affected, the most heavily myelinated sheaths, particularly in the posterior columns in the cervical and thoracic cord, appear to be more 3 . severely involved in the early lesions and that the changes are potentially reversible.

In subacute combined degeneration of theo cord, Lhermitte's sign is a common early symp- $\rightarrow$ tom and in the two patients described above was? the presenting one. A lesion of the posterior columns was present in all 11 patients with Lhermitte's sign, which suggests that demyelination at that site is the underlying pathological ${ }^{\omega}$ 
process. In neither of the two cases was there narrowing of the cervical canal, which supports the view of Jones (1964) that stretching of the fibres of the posterior columns on neck flexion is the mechanism by which the demyelinated fibres are stimulated. The disappearance of the symptoms and signs of the posterior column lesions within a few months of the commencement of treatment is explained by remyelination.

Lhermitte's sign is a much more common early symptom of subacute combined degeneration of the cord than is generally realized. Failure to appreciate this fact may lead to an erroneous diagnosis of multiple sclerosis, particularly if the patient is young as in case 2, or of cervical spondylosis in older people. As a consequence, correct treatment with vitamin $B_{12}$ may be delayed until irreversible spinal cord lesions have developed.

\section{REFERENCES}

Alajouanine, Th., Thurel, R., and Papaïoanou, C. (1949). La douleur à type de décharge électrique, provoquée par la flexion de la tête et parcourant le corps de haut en bas. Revue Neurologique, 81, 89-97.
Babinski, J., and Dubois, R. (1918). Douleurs à forme de décharge électrique, consécutives aux traumatismes de la nuque. Presse Médicale, 26, 64.

Hassin, G. B. (1933). Paraplegia in flexion and the symptom of Lhermitte. Archives of Neurology and Psychiatry, 29, 855-861.

Jones, A. (1964). Transient radiation myelopathy (with reference to Lhermitte's sign of electrical paraesthesia). British Journal of Radiology, 37, 727-744.

Lhermitte, J. (1918). Hypertrophie des muscles de la jambe consécutive à une lésion du nerf sciatique par balle. Presse Médicale, 26, 64.

Lhermitte, J., Bollak, and Nicolas, M. (1924). Les douleurs à type de décharge électrique consécutives à la flexion céphalique dans la sclérose en plaques. Un cas de forme sensitive de la sclérose multiple. Revue Neurologique, 31, 2 semestre, 56-62.

Lhermitte, J., Lévy, G., and Nicolas, M. (1927). Les sensations de décharge électrique; symptôme précoce de la sclérose en plaques, clinique et pathogénie. Presse Médicale, 35, 610-613.

Marie, P., and Chatelin, C. (1917). Note sur certains symptômes vraisemblablement d'origine radiculaire chez les blessées du crâne. Revue Neurologique, 24, ler jemestre, 143-144.

McAlpine, D., Lumsden, C. E., and Acheson, E. D. (1965). Multiple Sclerosis. A reappraisal. Livingstone: Edinburgh.

Pant, S. S., Asbury, A. K., and Richardson, E. P., Jr. (1968). The myelopathy of pernicious anaemia. Acta Neurologica Scandinavica, 44, Suppl. 35.

Patrick, H. T. (1930). The symptom of Lhermitte in multiple sclerosis. Archives of Neurology and Psychiatry, 23, 10751077. 